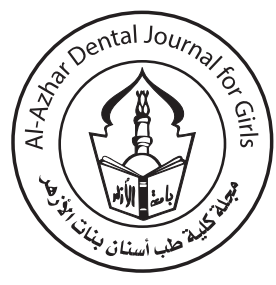

\title{
Evaluation of Dentoskeletal Changes Accompanying the Treatment of Class II Malocclusion by Advansync Appliance versus Intermaxillary Coil Spring Mechanics
}

\author{
May H. EL Mofty ${ }^{(1)}$, Samir A.Ibrahim ${ }^{(2)}$, Ossama S. EL-Shall ${ }^{(3)}$ and Wael A. Tawfik ${ }^{(4)}$
}

Codex : 44/1810

azhardentj@azhar.edu.eg

http://adjg.journals.ekb.eg

\section{KEYWORDS}

Class II division 1, Advansync, intermaxillary coil springs, fixed functional appliances.

\begin{abstract}
Objectives: The present study was designed to determine and compare the skeletal, dentoalveolar and soft tissue effects produced by the Advansync functional appliance and intermaxillary NiTi coil springs in the treatment of growing patients with Class II division 1 malocclusion. Subjects and methods: A sample of 19 growing patients, as evaluated by hand wrist radiographs, with age range 12-15 years was divided into two groups. Group I patients were treated with the Advansync appliance $(n=10)$ and Group II patients were treated using intermaxillary NiTi coil springs $(n=9)$. The study was conducted using lateral cephalograms taken before appliance insertion and immediately after appliance removal. Treatment changes were evaluated for each group and compared between both groups. Data were analyzed using Paired sample t-test for each group and Independent t-test for comparing groups together. Results: The use of Advansync and fixed appliances (Group I) resulted in significant decrease in SNA and ANB angles $(p \leq 0.001)$. Dental changes included retroclination of maxillary teeth, proclination and intrusion of mandibular teeth as well as mesialization of mandibular molars ( $\mathrm{p} \leq 0.001)$. On the other hand, SNA and ANB showed non-significant changes for patients treated with intermaxillary NiTi coil springs (Group II) $(\mathrm{p} \geq 0.05)$. While dental changes included retroclination of maxillary teeth, proclination and intrusion of mandibular teeth as well as mesialization of mandibular molars $(\mathrm{p} \leq 0.001)$ which were greater in Group II than Group I. The effects of both treatment modalities showed significant increases in total mandibular length and anterior facial height $(\mathrm{p} \leq 0.01$ and $\mathrm{p} \leq 0.05$ ) with no significant difference between both groups. Lower lip to $\mathrm{PtV}$ was the
\end{abstract}

Paper extracted from $\mathrm{PhD}$ thesis entitled "Evaluation of the Effects of Advansync Appliance versus Intermaxillary Coil Spring Mechanics on TMJ Morphology, Cone Beam Study".

1. Assistant Lecturer of Orthodontics, Orthodontic Department, Faculty of Dental Medicine, October University for Modern Sciences and Arts.

2. Professor and head of Orthodontic Department, Faculty of Dental Medicine for Girls, Al- Azhar University.

3. Professor of Oral Medicine, Periodontology, Diagnosis and Radiology Department and Vice Dean of Postgraduate Affairs, Faculty of Dental Medicine for Girls, Al-Azhar University.

4. Professor and head of Orthodontic Department, Faculty of Dental Medicine, October University for Modern Sciences and Arts. 
only soft tissue measurement with significant changes $(\mathrm{p} \leq 0.05)$ for each group and was non-significant when the two groups were compared together. Conclusion: Both treatment modalities were effective in treating Class II division 1 malocclusion. The Advansync appliance produced its effect through maxillary growth restriction and dentoalveolar changes. While the effects of intermaxillary NiTi coil springs were only dentoalveolar, but more than the Advansync appliance.

\section{INTRODUCTION}

Malocclusion is a problem with multifactorial aetiology of both genetic and environmental factors. Class II division 1 malocclusion is one of the most common types of malocclusions found ${ }^{(1)}$.

It can originate from discrepancies in the skeleton, the dentition, or both ${ }^{(2)}$. Mandibular retrusion is the most common feature for class II division 1 malocclusions ${ }^{(3,4)}$.

A variety of treatment options for Class II malocclusion have been introduced, of particular interest are intermaxillary appliances which act on both the maxilla and mandible to correct class II malocclusion ${ }^{(5)}$. They include intermaxillary elastics, appliances that act as substitutes for intermaxillary elastics and functional appliances ${ }^{(6)}$.

Intermaxillary Class II elastics are one of the most commonly used methods in present times, as they are practical, efficient and of low cost $(7,8,9)$. However, they have some disadvantages as they undergo progressive reduction in force magnitude and their elasticity maybe affected by several factors in the oral cavity such as $\mathrm{pH}$ and temperature ${ }^{(10,11)}$. In addition, latex elastics may cause allergic reactions $^{(12,13)}$.

However, closed Nickel Titanium (NiTi) coil springs maybe a better substitute as they generate lower and more continuous forces that are affected to a lesser degree with humidity and $\mathrm{pH}$. This characteristic of better force maintenance may cause faster and more physiologic movement with minimal aggression to dental and periodontal tissues ${ }^{(14,15)}$.
Several appliances are used as substitutes for intermaxillary Class II elastics such as Calibrated Force Module, Alpern Class II Closers, Saif Spring and CS 2000 Class II Springs were coil springs are placed instead of elastics distal to the mandibular molars and mesial or distal to the maxillary canines ${ }^{(16-19)}$.

Functional appliances are another intermaxillary treatment modality commonly used for growing patients with skeletal Class II division 1 malocclusion due to a retruded mandible. They include a range of removable and fixed devices that are designed to alter the position of the mandible, resulting in orthopaedic and orthodontic changes ${ }^{(20,21)}$. The use of fixed functional appliances in particular has the advantages of requiring minimal patient compliance and ensuring a constant anterior positioning of the mandible during the treatment period ${ }^{(22,23)}$. One of the commonly used rigid fixed functional appliances is the Herbst appliance, where several studies have investigated its effects and compared it to the effects of other functional appliances ${ }^{(24-27)}$.

Advansync appliance is a modification of the Herbst appliance, which is also known as Molar to Molar appliance. The Advansync appliance's design, which utilizes only the first permanent molars, allows correcting dental malocclusion simultaneously with the orthopaedic correction of class II, thus saving time ${ }^{(28)}$. Few studies have investigated the effects of Advansync appliance in relation to Mandibular Anterior Repositioning Appliance (MARA) and Class II elastics, but none has compared it to intermaxillary NiTi coil springs ${ }^{(28,29)}$.

Therefore, the purpose of the study was to compare the cephalometric skeletal, dental and soft tissue changes of the Advansync and intermaxillary NiTi coil springs after the treatment of Class II division 1 malocclusion in growing patients. 


\section{SUBJECTS AND METHODS}

A statistical power analysis was performed to determine the sample size. The alpha level was 0.05 $(5 \%)$; power of $80 \%$ and the suggested sample size was 18 for both groups ( 9 patients for each group). The study was conducted on 22 subjects selected from the clinic of the Orthodontic Department, Faculty of Dental Medicine for Girls Al- Azhar University. Over sampling was performed in case of dropouts. Consents were obtained from the patients' parents after the explanation of the aim and method of the study.

Growing patients (MP3 stages FG and G) of both genders with Class II division 1 malocclusion were selected. The inclusion criteria included skeletal class II relationship due to a deficient mandible with ANB angle greater than $5^{\circ}$ (as assessed from pre-treatment lateral cephalometric analysis). The selected patients needed a non-extraction treatment approach, they had normal or decreased lower facial height, as well as normal or decreased inclination of lower incisors and absence of any signs or symptoms of temporomandibular joint disorders.

Patients were divided into 2 groups equally. Group I initially included 12 patients that were treated with fixed functional appliance therapy using the Advansync appliance in combination with fixed appliance. Two patients did not continue treatment leading to a total of 10 patients who finished treatment with Advansync. Group II initially included 12 patients treated with intermaxillary nickel-titanium (NiTi) coil springs in combination with fixed appliance. Three patients did not continue treatment; therefore 9 patients finished treatment using intermaxillary NiTi coil spring mechanics.

For Group I patients treated with Advansync, upper and lower first molars were banded and the rest of the teeth were bonded by preadjusted edgewise appliances. Levelling arch wires were placed in sequential order until reaching 0.016 stainless steel arch wires for the bite to be sufficiently opened to provide a more comfortable mandibular advancement and easier mastication for the patient. Then bands were removed to place the Advansync appliance (Ormco, U.S.A). The Advansync appliance consisted of 4 partial crowns cemented on the upper and lower permanent first molars and 2 telescoping rods that connect the upper and lower crowns together on each side via screws by using a key supplied with the appliance. Crimpable spacers were also supplied to be placed onto the rods for additional activation or midline correction. Cephalometric records were taken before appliance insertion and immediately after appliance removal. Activation of the appliance was done $2-4 \mathrm{~mm}$ every

3 months for 6-9 months duration until moderate overcorrection was achieved (28). The activation was done by crimping C-spacers of appropriate sizes to the telescopic rods. Then the appliance was removed and class II elastics were used and the cases proceeded with normal orthodontic mechanics to finish.

For Group II patients banding and bonding procedures were done the same way as in Group I, but leveling arch wires were placed in sequential order until reaching $0.017 \times 0.025$ stainless steel arch wires for upper and lower teeth. Upper teeth were legated together from the upper right canine to the upper left canine before coil spring placement. Lower teeth were also legated together from the first molar on the right side to the first molar on the left side, to control proclination of lower incisors. The wire was also bent distally as in Group I patients. Then by using an orthodontic force gauge NiTi coil springs of suitable sizes that produced a force of 200 grams were chosen. The coil springs (Ormco, U.S.A) were attached bilaterally to the appliance for 5 to 8 months. The upper end of each spring was fixed to the hook on the maxillary canine bracket and the lower end to the hook on the mandibular first molar tube (16). No adjustments or reactivations were needed after the springs had been placed. Cephalometric records were obtained immediately before coil spring placement and at the 
end of treatment. Patients were instructed to remove them during eating.

\section{Cephalometric Analysis}

The lateral cephalograms representing the treatment groups were digitally traced using Anatomage version 5.1, San Jose, CA, U.S.A. Skeletal, dental and soft tissue variables were chosen from different cephalometric analyses $(28,30,29,31,32)$. The skeletal, dental and soft tissue measurements performed are illustrated in Figures 1, 2 and 3.

The results of the current study were collected, tabulated and statistically analyzed using Statistical Package for Social Science (SPSS) Version 20. The level of significance was set at $p \leq 0.05$. Descriptive statistics were calculated for each variable including mean and standard deviation. All data were explored for normality using Shapiro-Wilk test. Paired samples t-test was used to study the changes that occurred after treatment within each group and Independent samples t-test was used to compare changes between the two groups. Intra- observer reliability test was carried out using Concordance Correlation Coefficient (CCC).

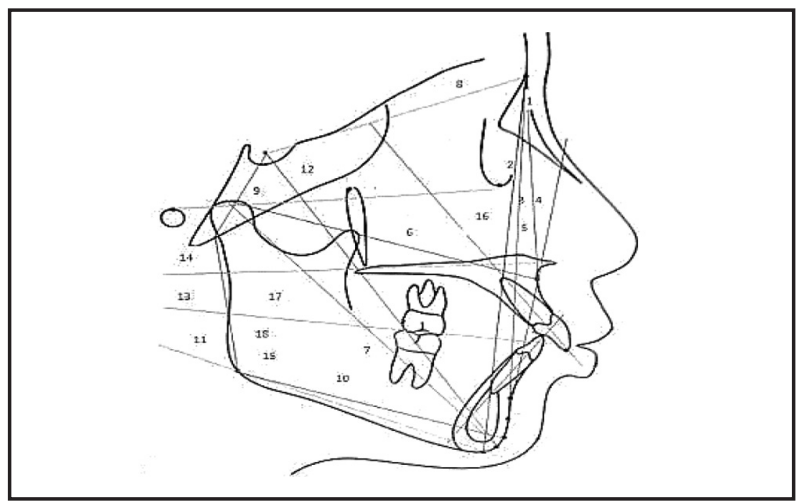

Fig. (1) Skeletal measurements 1-SNA angle, 2-SNB angle, 3- ANB angle, 4-Angle of convexity, 5-A to Nasion perpendicular, 6- Maxillary effective length, 7Mandibular effective length, 8- Anterior cranial base, 9- Posterior cranial base, 10- Corpus length, 11Mandibular plane\& SN , 12- Y Axis angle, 13-Occlusal to FH, 14- Palatal plane to Sella Nasion, 15- Gonial angle, 16- Anterior facial height, 17- Posterior facial height, 18- Ramus height.

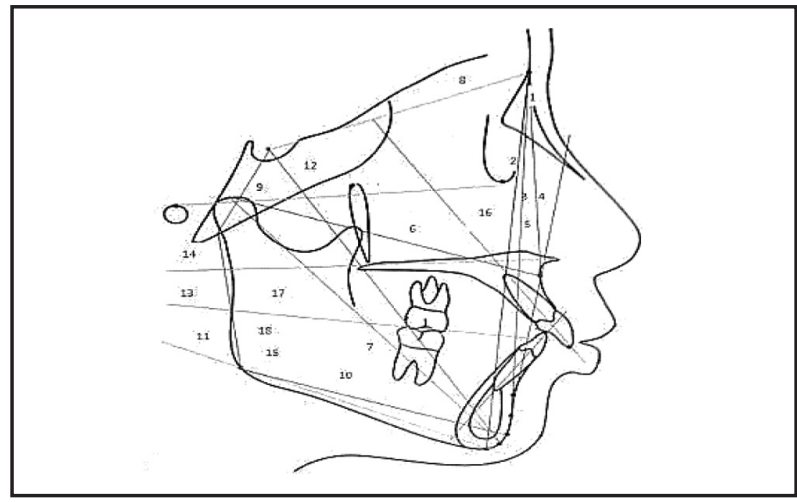

Fig. (2) Dental Measurements 1- Upper Incisor to SN angle, 2-Upper Incisor to NA (angle), 3-UI Position: upper incisor to NA (linear), 4-UI Height: upper incisor to PP (linear), 5- U6 Height: maxillary first molar cusp tip to PP, 6-U6 Position: maxillary first molar mesial surface to Pt V, 7 - Lower Incisor to MP, 8- Lower Incisor to NB (angle), 9-LI Position: lower incisor to NB (linear), 10- LI Height: lower incisor to MP, 11- FMIA: Lower incisor to FH, 12- L6 Height: mandibular molar cusp tip to MP, 13- L6 Position: mandibular first molar mesial surface to Pt V, 14- Overbite, 15- Overjet, 16Interincisal angle

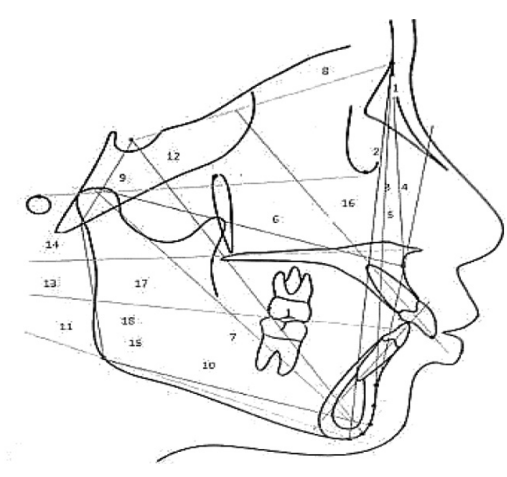

Fig. (3) Soft tissue measurements 1-Facial angle, 2-Subnasale to H plane, 3-H-angle, 4-Facial convexity(G' SnPog'), 5-Nasolabial angle, 6- Upper lip to E-line, 7- Lower lip to E-line, 8- Upper lip to Pt V, 9-Lower lip to Pt V,10Mentolabial sulcus depth

\section{RESULTS}

The patients within each group had very similar ages and gender distribution, while the overall follow up time was slightly more for group II treated with the coil spring mechanics as shown in table 1.

To determine accuracy of the method, cephalometric measurements were retraced and 
Table 1: Descriptive statistics comparing sample characteristics for the study groups.

\begin{tabular}{|c|c|c|c|c|c|c|}
\hline & \multicolumn{2}{|c|}{ Age } & \multicolumn{2}{c|}{ Observation Time } & \multicolumn{2}{c|}{ Gender } \\
\hline & Mean & SD & Mean & SD & Male & Female \\
\hline Group I (N=10) & 12.97 & 1.03 & 2.32 & 0.39 & $40 \%$ & $60 \%$ \\
\hline Group II (N=9) & 12.96 & 1.04 & 2.52 & 0.44 & $44.4 \%$ & $55.5 \%$ \\
\hline
\end{tabular}

remeasured by one investigator. The results of the intra-observer reliability test showed a range between very good to excellent reliability for both groups.

When the initial records of the two groups were compared the dentoskeletal characteristics of the two groups were generally similar except for two measurements, the posterior facial height, where patients in Group I had an increased posterior facial height than Group II and the height of upper molar which was increased in Group II more than Group I.

The anteroposterior measurements for Group I patients treated with Advansync appliance showed significantly decreased SNA angle, ANB angle and angle of convexity. While mandibular length was significantly increased and the rest of the skeletal anteroposterior measurements showed no significant changes. The skeletal vertical measurements for Group I indicated that the anterior and posterior facial heights increased significantly, while other measurements showed no significant effects.

Maxillary dental changes after treatment with Advansync appliance for Group I revealed a highly significant decrease in the angles of upper incisor to $\mathrm{SN}$, upper incisor to

NA and the distance between upper central to NA. However the height of upper incisor and the position and height of upper molar did not show any significant outcome.

Mandibular dental results for group I reported significant proclination and intrusion of lower incisors as revealed from statistically significant increase in lower incisor to MP and

NB angles as well as increase in the position of lower incisor to NB, while the height of lower incisor to MP decreased. Mesialization of the first molars occurred as the linear measurement between lower molar and PtV increased significantly. However there were no significant changes in the height of lower first molars. Maxillary and mandibular dental changes lead to a significant reduction in overjet and overbite.

Soft tissue changes for group I were not statistically significant except for lower lip to PtV, which showed significant increase when comparing pre-treatment to post-treatment measurements.

For group II patients treated with the coil spring mechanics, there were no significant changes for skeletal measurements except for mandibular length and anterior facial height which significantly increased. However the rest of the skeletal anteroposterior and vertical measurements showed no statistically significant outcomes.

Maxillary dental changes for group II had similar changes as in group I, where a highly significant decrease in the angles of upper incisor to $\mathrm{SN}$, upper incisor to NA and the distance between upper central to NA were present. While the height of upper incisor and the position and height of upper molar did not show any significant changes.

Mandibular dental results for group II, as in group I, reported significant proclination and intrusion of lower incisors as interpreted from statistically significant increase in lower incisor to MP and NB 
angles as well as increase in the position of lower incisor to $\mathrm{NB}$, while the height of lower incisor to MP decreased. Mesialization of the first molars occurred as the linear measurement between lower molar and PtV increased significantly. However there were no significant changes in the height of lower first molars. Intermaxillary dental measurement changes showed a significant reduction in overjet and overbite. Soft tissue changes for group II were not statistically significant except for lower lip to $\mathrm{PtV}$, which showed significant increase.

When comparing skeletal anteroposterior measurements between the two groups, group I showed significant decrease in SNA angle, ANB angle, angle of convexity and A-nasion perpendicular, than Group II as shown in table 2. All other skeletal anteroposterior and vertical measurements showed no statistical significant changes between the two groups.

When comparing maxillary dental measurements between the two groups, the angles of upper incisor to $\mathrm{SN}$, upper incisor to NA and the distance between upper central to NA were significantly reduced in Group II more than Group I. However the height of the upper incisor and the position of upper molar showed no significant changes between the two groups, but the height of upper molar reported a statistically significant increase in Group II than Group I, table 3. Whereas, mandibular dental changes were similar between the two groups and were statistically non-significant. When comparing intermaxillary dental measurements between groups I and II, the overjet reduced significantly more in group II compared to group I. However differences in overbite and inter-incisal angle were not statistically significant as revealed in table 4.Regarding soft tissue measurement, both groups showed no statistically significant changes for all soft tissue measurements.

Table 2: Comparison of anteroposterior skeletal changes between treatment groups

\begin{tabular}{|c|c|c|c|c|c|c|}
\hline \multirow[t]{2}{*}{ Measurements } & \multicolumn{2}{|c|}{ Group I $(\mathrm{N}=10)$} & \multicolumn{2}{|c|}{ Group II (N=9) } & \multirow{2}{*}{ p-value } & \multirow{2}{*}{ Sig. } \\
\hline & Mean & SEM & Mean & SEM & & \\
\hline SNA & -1.02 & 0.23 & -0.02 & 0.02 & $<0.001$ & * \\
\hline SNB & 0.06 & 0.09 & 0.02 & 0.01 & 0.179 & NS \\
\hline ANB & -1.62 & 0.26 & -0.05 & 0.02 & $<0.001$ & $*$ \\
\hline Angle of convexity & -1.05 & 0.23 & -0.36 & 0.18 & $<0.001$ & * \\
\hline A-Nasion Perpendicular & -0.55 & 0.30 & -0.01 & 0.09 & $<0.001$ & $*$ \\
\hline Midfacial Length & 0.03 & 0.07 & 0.05 & 0.06 & 0.502 & NS \\
\hline Mandibular length & 1.01 & 0.58 & 0.99 & 0.27 & 0.922 & NS \\
\hline Corpus Length & 0.20 & 0.21 & 0.15 & 0.09 & 0.498 & NS \\
\hline Anterior cranial base & 0.13 & 0.13 & 0.09 & 0.14 & 0.516 & NS \\
\hline Posterior Cranial base & 0.06 & 0.16 & 0.03 & 0.13 & 0.651 & NS \\
\hline
\end{tabular}

$S D=$ Standard Deviation, $n=$ number, $N S=$ Non- Significant $p>0.05, p=$ probability level, Sig = Significance, *: Significant at $P \leq 0.001$ 
Table 3: Comparison of maxillary dental changes between treatment groups

\begin{tabular}{|c|c|c|c|c|c|c|}
\hline \multirow{2}{*}{ Measurements } & \multicolumn{2}{|c|}{ Group I $(\mathrm{N}=10)$} & \multicolumn{2}{|c|}{ Group II (N=9) } & \multirow{2}{*}{$p$-value } & \multirow{2}{*}{ Sig. } \\
\hline & Mean & SEM & Mean & SEM & & \\
\hline UI-SN angle & -5.3 & 0.45 & -6.32 & 0.47 & $<0.001$ & $*$ \\
\hline UI-NA angle & -4.33 & 0.42 & -5.65 & 0.64 & $<0.001$ & $*$ \\
\hline Position UI-NA (mm) & -1.57 & 0.30 & -2.35 & 0.17 & $<0.001 *$ & $*$ \\
\hline Height UI-PP (mm) & 0.15 & 0.32 & 0.31 & 0.20 & 0.197 & NS \\
\hline Position U6-PtV (mm) & -0.49 & 0.32 & -0.55 & 0.33 & 0.685 & NS \\
\hline Height U6-PP (mm) & 0.15 & 0.14 & 0.32 & 0.17 & 0.025 & $* *$ \\
\hline UI-SN angle & -5.3 & 0.45 & -6.32 & 0.47 & $<0.001$ & $*$ \\
\hline UI-NA angle & -4.33 & 0.42 & -5.65 & 0.64 & $<0.001$ & $*$ \\
\hline
\end{tabular}

$S D=$ Standard Deviation, $n=$ number, NS= Non-Significant $p>0.05, p=$ probability level,

Sig $=$ Significance, *: Significant at $P \leq 0.001$, **: Significant at $P \leq 0.05$

Table 4: Comparison of maxillary dental changes between treatment groups

\begin{tabular}{|c|c|c|c|c|c|c|}
\hline \multirow{2}{*}{ Measurements } & \multicolumn{2}{|c|}{ Group I (N=10) } & \multicolumn{2}{c|}{ Group II (N=9) } & \multirow{2}{*}{ p-value } & Sig. \\
\cline { 2 - 6 } & Mean & SEM & Mean & SEM & \\
\hline Over jet & -5.23 & 0.20 & -6.00 & 0.20 & $<0.001$ & $*$ \\
\hline Over bite & -2.05 & 0.40 & -2.12 & 0.48 & 0.727 & NS \\
\hline Inter-incisal angle & 2.16 & 1.27 & 2.65 & 1.70 & 0.475 & NS \\
\hline
\end{tabular}

$S D=$ Standard Deviation, $n=$ number,$N S=$ Non-Significant $p>0.05, p=$ probability level,

Sig $=$ Significance, $*$ : Significant at $P \leq 0.001$

\section{DISCUSSION}

Class II division 1 malocclusion is one of the most common types of malocclusions found in orthodontic practice $^{(1)}$. It can originate from skeletal imbalance between the maxilla and mandible, where mandibular retrusion is the most common feature for this type of malocclusion ${ }^{(3,4)}$.

A variety of treatment options for Class II division 1 malocclusion have been introduced. Of particular interest are intermaxillary treatment modalities which act on both the maxilla and mandible to correct Class II malocclusion ${ }^{(5,6)}$.
A commonly used intermaxillary treatment modality is intermaxillary elastics. They are practical, efficient and of low cost, but they undergo progressive reduction in force magnitude and their properties are affected by humidity and temperature $^{(10,11)}$. On the other hand, closed NiTi coil springs can be used as substitutes as they are superior to intermaxillary elastics in generating lower and more continuous forces that are affected to a lesser degree with humidity and $\mathrm{pH}^{(14,15)}$. No recent studies were found describing skeletal, dental and soft tissue effects of intermaxillary NiTi coil springs in Class II division treatment. 
Functional appliances are an alternative intermaxillary treatment modality commonly used for growing patients with skeletal Class II malocclusion due to a retruded mandible. They include removable and fixed devices that are designed to alter the position of the mandible, to induce supplementary lengthening ${ }^{(20)}$. As the mandible is postured forward, growth of the distracted condylar head and remodeling of the glenoid fossa take place ${ }^{(21)}$.

The Advansync is one of the recently developed rigid fixed functional appliances that have still not yet been well investigated (28-30). It utilizes only the first permanent molars, thus allowing the placement of preadjusted edgewise appliances at the beginning of treatment, causing dental and orthopaedic correction simultaneously and hence saving time ${ }^{(28,30)}$.

\section{Results' interpretation}

\section{Skeletal Changes:}

Group I patients treated with the Advansync appliance experienced maxillary growth restriction as indicated by 1.02 decreases in SNA angle. Although the appliance did not significantly affect the anteroposterior position of the mandible (SNB; $p>0.05$ ), there was a highly significant improvement in the intermaxillary skeletal relationship (ANB; $\mathrm{p}<0.001$ and angle of convexity; $\mathrm{p}<0.01)$ and an increase in the total mandibular length $(\mathrm{Cd}-$ $\mathrm{Gn} ; \mathrm{p}<0.001)$. There were no significant changes regarding skeletal vertical measurements except for the anterior and posterior facial heights that experienced a significant increase $(\mathrm{p}<0.05)$.

The results of the present study were in agreement with previous studies that used Advansync appliance for Class II division 1 treatment ${ }^{(29,30)}$.

Group II patients treated with intermaxillary coil springs did not experience any significant skeletal anteroposterior changes except for a significant increase in the total mandibular length. These out comes were similar to the findings for a previous study reported except for the SNA angle, where it was found that treatment with Class II elastics showed slight maxillary skeletal growth restriction ${ }^{(29)}$. This disagreement may be due difference in study design, where they compared their results to a control group, whereas, a control group was not included in the present study. Another investigation also agreed with the present study as they stated that Class II elastics produced a more vertically directed increase in mandibular length that did not affect SNB angle ${ }^{(8)}$.

Contradicting these results, a previous study made where CS 2000 Class II springs were used, which stated that intermaxillary improvement occurred due to anterior projection of point B. Although CS 2000 Class II springs were placed from upper canines to mandibular molars, as the intermaxillary coil springs used in this study, CS 2000 Class II springs was considered a noncompliant appliance which was not removed by the patient. Consequently, unlike the intermittent forces produced by intermaxillary springs used in the current study, CS 2000 Class II springs exert continuous forces which may have lead to anterior projection of point $\mathrm{B}^{(19)}$.

\section{Dental Changes:}

The upper incisors in Group I, treated with Advansync appliance, were significantly retroclined (U1-SN $\left.{ }^{\circ}, \mathrm{U}_{1-N A^{\circ}}, \mathrm{U} 1-\mathrm{NAmm} ; \mathrm{p}<0.001\right)$ whereas the upper molars did not experience any significant changes. These outcomes were in accordance with previous studies reported for the for the Advansync appliance $(28,30)$. Another study also had similar findings except for extrusion of the upper incisors which may be due to difference in fixed appliance mechanics ${ }^{(29)}$.

Lower incisors in the present study showed significant proclination as indicated by $5.38^{\circ}$ increase in the lower incisor angulation relative to mandibular plane as well as significant intrusion. Both changes of maxillary and mandibular incisors contributed to the significant improvements that 


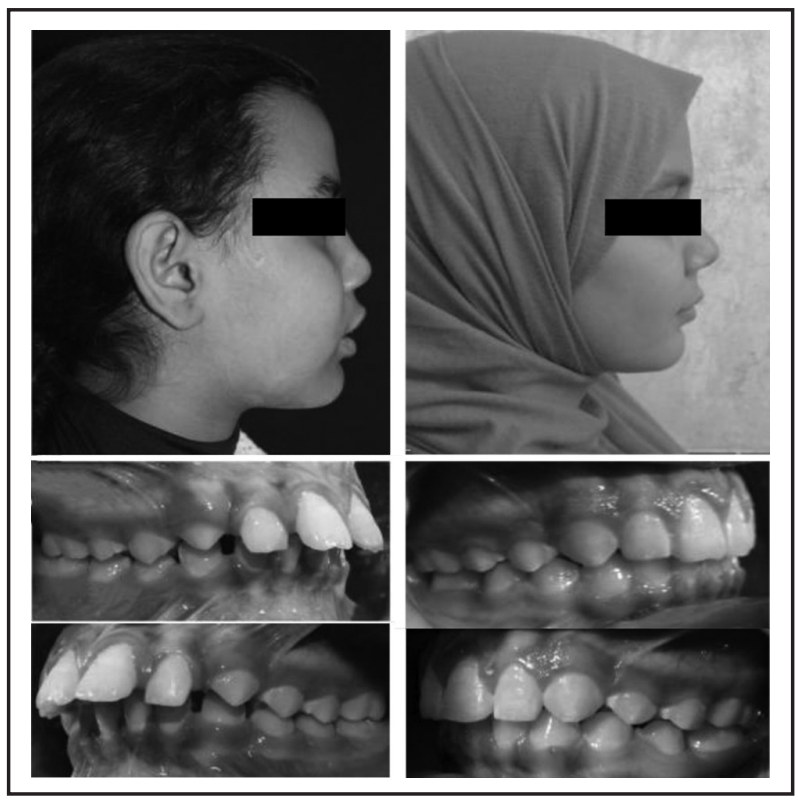

Fig. (4) Pre and post-treatment extra-oral and dental views for a case treated with Advansync appliance

occurred for the overbite and overjet. These results were similar to the ones reported for the treatment with the Advansync appliance (28-30), except for two studies that did not report intrusion of lower incisors ${ }^{(28,30)}$ and this may be due to different fixed appliance mechanics or the degree of overbite present in their samples.

The Advansync appliance caused mesialization of mandibular molars of $2.95 \mathrm{~mm}$ (L6- PtV; p< 0.001 ) which assisted in establishing a Class 1 molar relation. This was also a common finding reported among the studies using the Advansync appliance (28- 30).

Dental changes resulting from coil spring treatment for Group II were similar to those for Group I and these findings were similar to previous studies reported for the treatment with Class II elastics ${ }^{(19,29)}$.

When comparing both groups, dentoalveolar improvements produced by intermaxillary coil springs were more than Advansync and this was in agreement to a previous study ${ }^{(29)}$.

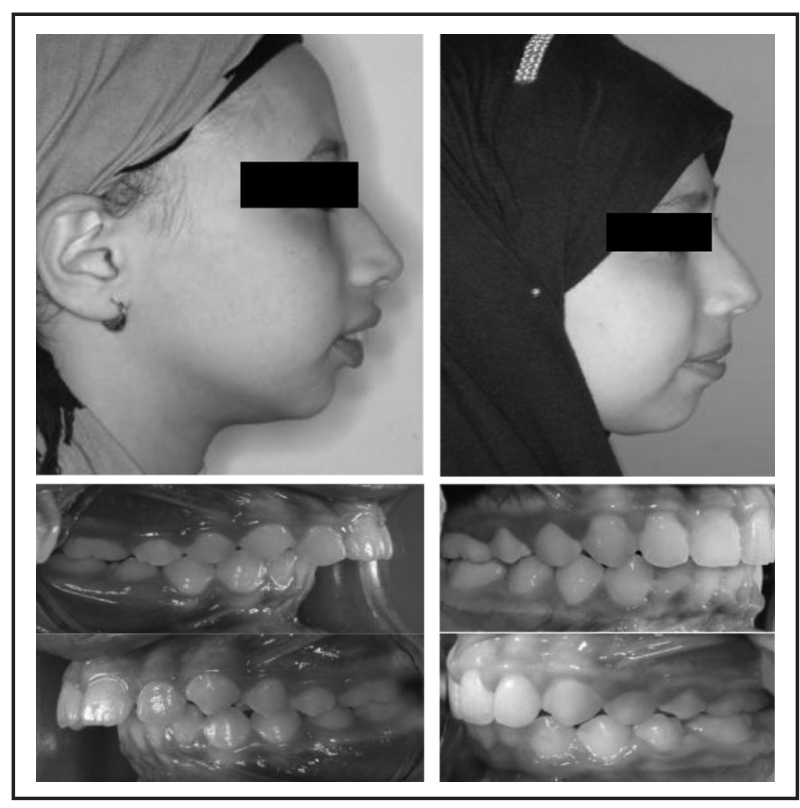

Fig. (5) Pre and post-treatment extra-oral and dental views for a case treated with intermaxillary coil spring mechanics

\section{Soft Tissue Changes:}

Regarding soft tissue outcomes for Groups I and II, there were no statistically significant changes except for protrusion of the lower lip. Studies that investigated soft tissue changes due to Advansync treatment were contradictory. A study reported that no significant changes affected the soft tissues after Advansync treatment ${ }^{(29)}$. Whereas, another study stated that upper lip, lower lip and $\mathrm{H}$ angle improved after treatment ${ }^{(30)}$.

When both groups were compared together, no statistically significant changes were found for all soft tissue measurements and these findings were in agreement with a previous study performed on Advansync and intermaxillary elastics ${ }^{(29)}$.

\section{CONCLUSIONS}

On the bases of the results obtained from this study, the following conclusions were drawn:

1. Advansync appliance and intermaxillary NiTi coil springs were both successful in treating Class II division 1 malocclusion in growing patients. 
2. Class II division 1 treatment using either Advansync or intermaxillary coil springs had no effect on glenoid fossa morphology or TMJ spaces.

3. Advansync appliance produced skeletal improvement by causing maxillary growth restriction, whereas intermaxillary coil springs had no skeletal effects on the maxilla.

4. Both treatment modalities produced vertical changes by increasing the anterior facial height.

5. Both treatment modalities produced retroclination of upper incisors, proclination of lower incisor, thus improving the overjet, as well as mesialization of lower molars.

6. Intermaxillary coil springs produced more dentoalveolar improvements than Advansync appliance.

7. Lower lip position improved for both treatment modalities

8. Advansync appliance was more suitable for non compliant patients than intermaxillary coil springs as less patient co-operation was needed.

\section{REFERENCES}

1. Cozza P, Baccett Ti, Franchi L, De Toffol L and McNamara JA. Mandibular changes produced by functional appliances in Class II malocclusion: A systematic review. Am J Orthod Dentofac Orthop. 2006; 129:1-12.

2. Proffit WR, Fields HW and Sarver DM. Orthodontic treatment planning: limitations, controversies and special problems. In: Contemporary Orthodontics. St. Louis: Mosby, 2007: 296-297.

3. Dolce C, Mansour DA, McGorray SP and Wheelerd TT. Intrarater agreement about the etiology of Class II malocclusion and treatment approach. Am J Orthod Dentofac Orthop. 2012; 141:17-23.

4. Cassidy SE, Jackson SR, Turpin DL, Ramsay DS, Spiekerman $\mathrm{C}$ and Huang GJ. Classification and treatment of Class II subdivision malocclusions. Am J Orthod Dentofac Orthop. 2014; 145: 443- 451 .
5. Spalding P. Treatment of class II malocclusions. In: Bishara S. Textbook of orthodontics. St. Louis: WB Saunders, 2001: 351-352.

6. Papadopoulos MA. Non-compliance approaches for management of class II malocclusion. In: Skeletal Anchorage in Orthodontic Treatment of Class II Malocclusion: contemporary applications of orthodontic implants, miniscrew implants and miniplates. St. Louis: Mosby, 2015: 6-11.

7. Singh VP, Pokhrael PR, Pariekh K, Roy DK, Singla A and Biswas KP. Elastics in orthodontics: a review. Health Renaiss. 2012; 10: 49-56.

8. Tsarudis CS and Pancherz H. "Effective" TMJ and chin position changes in Class II treatment. Angle Orthod. 2008; 78: 813-818.

9. Yildirim E and Karacay S. Comparison of dentofacial effect of the Eureka Spring and intermaxillary elastics in the treatment of Class II malocclusion. Gulhane Med J. 2015; 57: 284-289.

10. Pithon MM, Mendes JL, Silva CA, Santos RL and Coqueiro RS. Force decay of latex and non-latex intermaxillary elastics: a clinical study. Eur J Orthod. 2016;38:39-43.

11. Borges JC, Gallo DB, Santana RM, Filho OG, Camargo ES and Tanaka OM. Influence of different beverages on the force degradation of intermaxillary elastics: an in vitro study. J Appl Oral Sci. 2013; 21: 145-149.

12. Santos RL, Pithon MM, Martins FO, Romanos MTV and Ruellas ACO. Cytotoxicity of the latex and nonlatex orthodontic elastomeric ligatures on L929 mouse fibroblasts. Braz Dent J. 2010; 21: 205-210.

13. Colomer SM, Hernandez PG, Romano FL, De Rossi A, Fukada SY, Filho PN, Consolaro A, Silva RAB and Silva LAB. Latex and non-latex orthodontic elastics: in vitro and in vivo evaluations of tissue compatibility and surface structure. Angle Orthod. 2016; 86: 278-284.

14. Pires BU, Souza RE, Filho MV, Degan VV, Santos JCB and Tubel CAM. Force degradation of different elastomeric chains and nickel titanium closed springs. Braz J Oral Sci. 2011; 10:167-170.

15. Chaudhari CV and Tarvade SM. Comparison of rate of retraction and anchorage loss using nickel titanium closed coil springs and elastomeric chain during the en-masse retraction: a clinical study. J Orthod Res. 2015; 3:129- 133.

16. Papadopoulos MA. Orthodontic Treatment of the Class II Non-compliant Patient: Current Principles and Techniques. Edingurgh: Mosby, 2006: 26. 
17. Mcsherry PF and Bradley H. Class II correction-reducing patient compliance: a review of the available techniques. $\mathrm{J}$ Orthod. 2000; 27: 219-225.

18. Vanlaecken R, Williams MO, Razmus T, Gunel E, Martin C and Ngan P. Class III correction using an inter-arch springloaded module. Prog Orthod. 2014; 15:1-11.

19. Lombardo L, Carlucci A, Cervinara F and Siciliani G.A new, non-compliance Class II correction strategy using nickeltitanium coilsprings.J World Fed Orthod.2015;4:40-49.

20. Southard TS, Marshall SD, Allareddy V, Uribe LMM and Holton NE. An evidence- based comparison of headgear and functional appliance therapy for the correction of Class II malocclusions. Semin Orthod. 2013; 19: 174-195.

21. Littlewood SJ. Functional appliances. In: Mitchell L, An Introduction to Orthodontics. United Kingdom: Oxford, 2013:248-249.

22. Nanda R and Kapila S. Current Therapy in Orthodontics. 1st edition. St.Louis: Mosby; 2010: 103-114.

23. Ritto AK and Ferreira AP. Fixed functional appliances- A classification. Funct Orthod. 2000; 17: 12-30.

24. McNamara JA and Howe RP. Clinical management of the acrylic splint Herbst appliance. Am J Orthod Dentofac Orthop. 1988; 94:142-149.

25. Barnetta GA, Higginsb DW, Majorc PW and Mird CF. Immediate skeletal and dentoalveolar effects of the crownor banded type Herbst appliance on class II division 1 malocclusion. Angle Orthod. 2008; 78: 361-369.
26. Baysal A and Uysal T. Dentoskeletal effects of Twin Block and Herbst appliances in patients with Class II division 1 mandibular retrognathy. Eur J Orthod.2014; 36:164-172.

27. Manni A, Pasini M, Mazzotta L, Mutinelli S, Nuzzo C, Grassi FR and Cozzani M. Comparison between an acrylic splint Herbst and an acrylic splint miniscew-Herbst for mandibular incisor proclination control. Int J Dent. 2014;1-7.

28. Al-Jewair TS, Preston C. B, Moll EM and Dischinger T. A comparison of the MARA and the Advansync functional appliances in the treatment of Class II malocclusion. Angle Orthod. 2012; 82: 907-914.

29. Jayachandran S, Wiltshire WA, Hayasaki SM and Pinheiro FHSL. Comparison of Advansync and intermaxillary elastics in the correction of Class II malocclusions: A retrospective clinical study. Am J Orthod Dentofac Orthop. 2016; 150: 979-988.

30. Ateia HA: Evaluation of the role of Advansync appliance in treatment of class II division 1 malocclusion. Master thesis, AL-Azhar University Girls' Branch, Egypt 2013.

31. Atik E, Guven BA and Kocadereli I. Soft tissue effects of three different Class II/1- camouflage treatment strategies. J Orofac Orthop. 2017; 78:153-165.

32. Nishanth B, Gopinath A, Ahmed S, Patil N, Srinivas K and Chaitanya A. Cephalometric and computed tomography evaluation of dentoalveolar/soft-tissue change and alteration in condyle-glenoid fossa relationship using the Power Scope: A new fixed functional appliance for Class II correction- A clinical study.Int JOrthod Rehabil.2017; $8: 41-50$. 